\title{
Safe remaining lifetime assessment of power plant steam boilers
}

\author{
V. Mentl ${ }^{1} \&$ V. Liska ${ }^{2}$ \\ ${ }^{1}$ Department of Material Science and Technology, \\ University of West Bohemia, Plzen, Czech Republic \\ ${ }^{2}$ Accredited Labs., Skoda Research Ltd., Plzen, Czech Republic
}

\begin{abstract}
Energy producing power plants are designed for an operational period of $20-30$ years. During this period, inspections are realized to investigate the operational capability of the respective components and the plant as a whole, and when the designed time is approaching its limit, crucial questions are raised with respect to the continuing possible operation, and its safety and risks that stem from the fact that the continuous degradation of material property has occurred during the lifetime of service as a result of service conditions, e.g. high temperatures, fatigue loading etc.

The inspection of the boiler and the assessment of its future operational capability should ensure the safe operation and minimization of the failure risks that can cause not only economic losses.

This paper summarizes the results of non-destructive (NDT) and destructive mechanical and metallographic tests performed in order that the degradation of material property of the decisive Steam Turbine Boiler Components due to service conditions could be evaluated and the resulting residual lifetime assessed. On the basis of performed examination, the results provided the customer with recommendations relating to the future safe and reliable operation of the boiler. Keywords: material degradation, remaining safe lifetime assessment, steam turbine boiler components.
\end{abstract}




\section{Introduction}

\subsection{Boiler description and technical details}

Inspected Equipment: The boiler was approximately 20 years old and was in permanent service

Service Parameters: Steam Output: $\quad 730$ tons/hrs Steam Pressure: $\quad 9,2 \mathrm{MPa}$

Fuel:

Year of Production: Steam Temperature: $515^{\circ} \mathrm{C}$

Service Hours:

Natural Gas (predominantly)/ Oil 1983

approx. 120000

The boiler was made of common steels used in boilers produced 20-25 years ago in the 1980s. High temperature tube banks and headers were made of $10 \mathrm{CD} 9$ 10 2,25Cr1Mo ferritic low-alloy steel (SA 335 P22 equivalent), the lower temperature superheaters were made of $15 \mathrm{CD} 2-050,5 \mathrm{Cr} 0,5 \mathrm{Mo}$ low-alloy steel with limited creep resistance.

\section{Objectives of the destructive and non-destructive testing}

The objectives of the inspection can be listed as follows:

- $\quad$ To perform a comprehensive cold shut-down inspection of the Boiler.

- $\quad$ The inspection should provide the company representatives with reliable information about the technical condition of the boiler and recommendations relating to its possible safe-life extension.

- The inspection should be based on the evaluation of material property degradation of selected structural components of the boiler by means of both non-destructive techniques and destructive mechanical testing methods.

\section{Description of inspection techniques}

The inspection of the Boiler was performed by an expert team of under No. 1047 by Czech Institute for Accreditation in Prague Accredited Testing Laboratories, Skoda Research Ltd., Pilsen, Czech Republic, [1].

The in-situ non-destructive techniques (NDT) included:

- Visual inspection

- Magnetic particle examination

- Ultrasonic examination

- $\quad$ Ultrasonic thickness measurement

- Replica Testing

- Microhardness measurement 
In situ inspected components included:

- Main Steam Pipeline

- De-Super Heater Nozzle

- Steam Drum

- $\quad$ High Temperature Superheater Headers S4 and S5

- Intermedial Temperature Superheater Headers S2 and S3

- Economizer

- $\quad$ Furnace - Water Wall Tubes and Superheater Tubes

- Water Wall Headers in Penthouse

- $\quad$ Bottom Space - Mud Drum and Header K10

- $\quad$ Regenerative Air Heater

- Burners

Destructive and non-destructive tests of tube samples removed from most high temperature affected boiler localities were performed at SKODA Research Ltd., Pilsen, Czech Republic. The respective tube samples were removed from the Superheater Tubes (Inlet and Outlet), Economizer and Water walls.

These included:

- Visual examination of the tube samples surfaces

- Tube cross section dimension measurement

- Magnetic particle inspection of tube surfaces

- Mechanical (tensile to rupture and hardness) tests of base materials

- Metallographic examination of tube materials

- Measurement of the scale deposit thickness on water side

- Chemical analysis of scale deposits

\section{Inspection findings}

Examination performed on the tube samples removed from the abovementioned locations resulted in the conclusion that no significant material property degradation of tested tubes was observed [1]. On the basis of NDT and replica testing it was concluded that no significant material degradation of tested tubes has occurred yet [2].

The results of mechanical tests and the comparison of obtained results with the standard mechanical property values of the specific steels proved that the material of tubes is in a relatively good condition not severely affected by service with respect to the service hours. Both the yield point, ultimate strength and elongation values of the tube samples were well above minimum standard values and did not reveal any substantial degradation of mechanical properties of samples in question.

\section{Remaining lifetime assessment}

Design of structural parts operating in creep range (in case of steels above 450 degCelsius) is primarily based on the detailed knowledge of structural materials properties at higher temperatures. The creep curves are necessary in cases where 
the time dependant increase of plastic creep deformation can limit the lifetime of the structure (e.g. in the case of high temperature steam turbine rotor blades), whereas the time to rupture is the limiting factor in the case of boilers.

The basic information of a material behaviour is represented by experimentally determined stress vs. time-to-rupture curves, which in case of the steels used in the examined boiler is well-known in spite of the fact that the values for real operational times (up to $200000 \mathrm{hrs}$ ) are extrapolated from experimental values only rarely obtained for times longer than 20000 or 30000 hrs.

The safety factor (in general of $\mathrm{k}=1,5$ value) is applied for safe service life evaluation. It takes into account all the uncertainties which a designer is not able to include quantitatively and accurately enough into the reliability and safety calculations. These can be e.g.

- natural intrinsic scatter of the stress vs. time-to-rupture data. (Experimental experience proves that up to $20-25 \%$ stress scatter must be considered.)

- $\quad$ service temperature changes not assumed by design

- $\quad$ service stress changes caused by internal pressure irregularities

- stress increase caused by dimensional changes of the structural components due to creep and corrosion.

The stress vs. time to rupture curves at different temperatures obtained for the respective material, can be transformed into one single-curve relationship between stress and the Larson-Miller Parameter, which is defined as follows:

where

$$
\mathrm{LMP}=\mathrm{T}(\mathrm{C}+\log \mathrm{t}),
$$

$\mathrm{T} \quad$ is the service temperature in degrees of Kelvin

$\mathrm{C}$ is the constant generally of $\mathrm{C}=20$ value used for steels of this type, and

$\mathrm{t}$ is the operational time of the structure or component.

In the case of the respective boiler, the remaining lifetime assessment was performed for the structural parts where the creep damage must have been expected, i.e. for

- main steam pipeline, and

- $\quad$ high temperature (HT) superheater tubes and headers.

To make use of stress vs. LMP relationship, the real stresses were calculated on the basis of the largest measured tube diameter and the lowest tube wall thickness, so that the worst case was taken into account in order that the conclusions were conservative and at the "safe side".

The real service stress in a component and the corresponding Larson-Miller Parameter (LMP) value determine the real working point (e.g. point No.1 in Fig. 1) of the component within the stress vs. LMP diagram. In this point, the life of the component has not been exhausted yet. Moving further along the horizontal line (increasing thus service time at the same stress and temperature) we reach the creep rupture curve (point No.2), what should result in the component damage. 


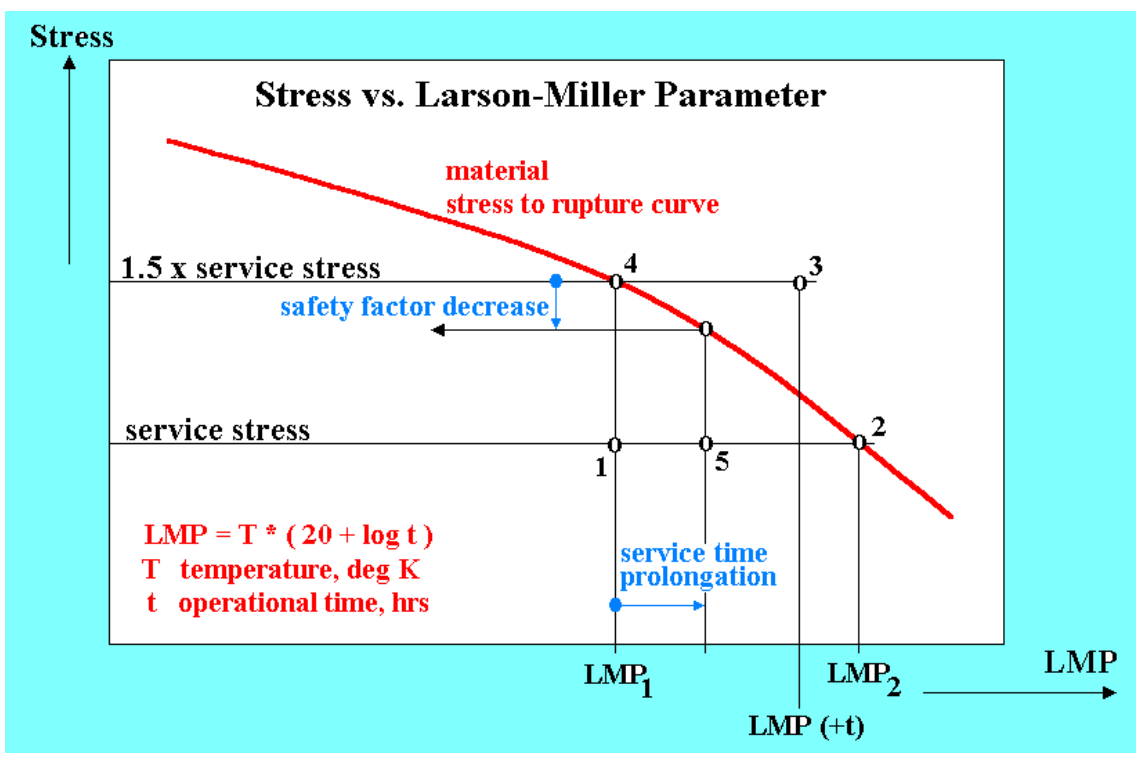

Figure 1: $\quad$ Stress vs. Larson-Miller Parameter relationship.

The remaining life of the respective component can thus be determined from the difference of LMPs between points No.1 and No.2.

Nevertheless the stress safety factor $(\mathrm{k}=1,5)$ should be taken into consideration and similarly higher computational temperature assumed. (Standards in case of superheaters recommend to use the temperature increase of up to $70 \mathrm{degC}$.) After the service stress is increased by the safety factor of 1,5 and LMP recalculated for $(T+70)$ temperature, the point No.3 within the stress - LMP diagram is received that includes all the safety requirements. This point can be situated both under and/or above the creep to rupture curve, what in the second case may represent an unsafe situation.

If the original design of an individual component was performed correctly, the following situation can be usually observed:

- the point No.1 represents the real situation in the time of inspection and should be below the stress - LMP curve,

- after taking into consideration the stress safety factor, the point No.4 is situated on the stress - LMP curve, if the inspection was performed just close to the end of the designed service hours.

We can thus prolong the service hours of the structure under the assumption that safety factor will decrease, see Fig.1, what should result in more frequent check of material condition and behaviour and careful control of temperatures, pressures and of all other decisive parameters. (A continued operation for time $\Delta \mathrm{t}$ above the point No.1 in Fig. 1 increases the LMP to LMP $=\mathrm{T}^{*}(20+\log (\mathrm{t}+$ $\Delta \mathrm{t})$ ), e.g. point No.5, what results in decrease of the safety factor below the value of $\mathrm{k}=1,5$. 
The calculation described above was performed for the most by creep damage affected components of the boiler, i.e. for the main steam pipeline and hightemperature superheaters.

The experimental stress vs. time-to-rupture curves for the steels in question were transformed to the stress vs. Larson-Miller Parameter diagram.

S4 HT Superheater steel points, Fig.2, of both the header and the tube banks are far from the creep to rupture curve and even after taking into consideration the safety factor and temperature increase the resulting points are in the „safe“ area of stress vs. LMP diagram.

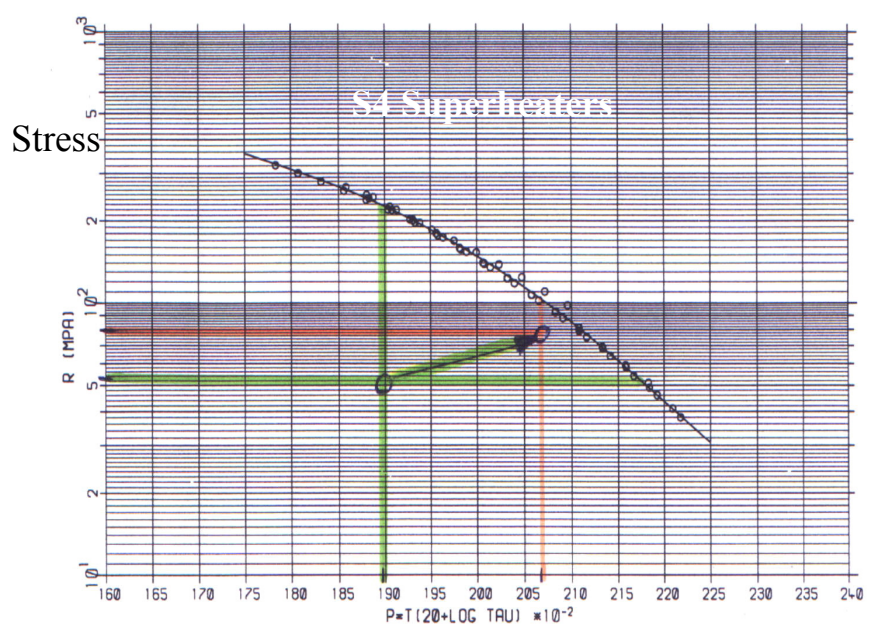

Larson-Miller Parameter

Figure 2: $\quad$ Stress vs. Larson-Miller Parameter relationship, Superheaters S4.

S5 HT Superheater steel points of both the header and the tube banks, Fig.3, are rather far from the creep to rupture curve but after taking into consideration the safety factor and temperature increase, the resulting point of the header falls directly on the stress to rupture curve and the point representing the situation of tubes is far beyond the curve in the potentially dangerous area. The safe life of both the components has thus already been exhausted and further operation will be in progress with lower safety factor only according to this methodology.

The main steam pipeline points, see Fig.4, are in safe area when safety factor is not applied. If the safety factor and temperature increase are taken into consideration, both the pipelines fall into unsafe area, safe lifetime was thus exhausted and further operation can be realized with decreasing safety only.

On the basis of the above-mentioned situation, the remaining lifetimes of the decisive components were calculated, see Tab.1.

The service stresses in the components were calculated on the basis of measured component diameters and wall thicknesses. On the basis of resulting "safe" points in the stress vs. LMP diagrams for the components in question, the following conclusions can be made: 


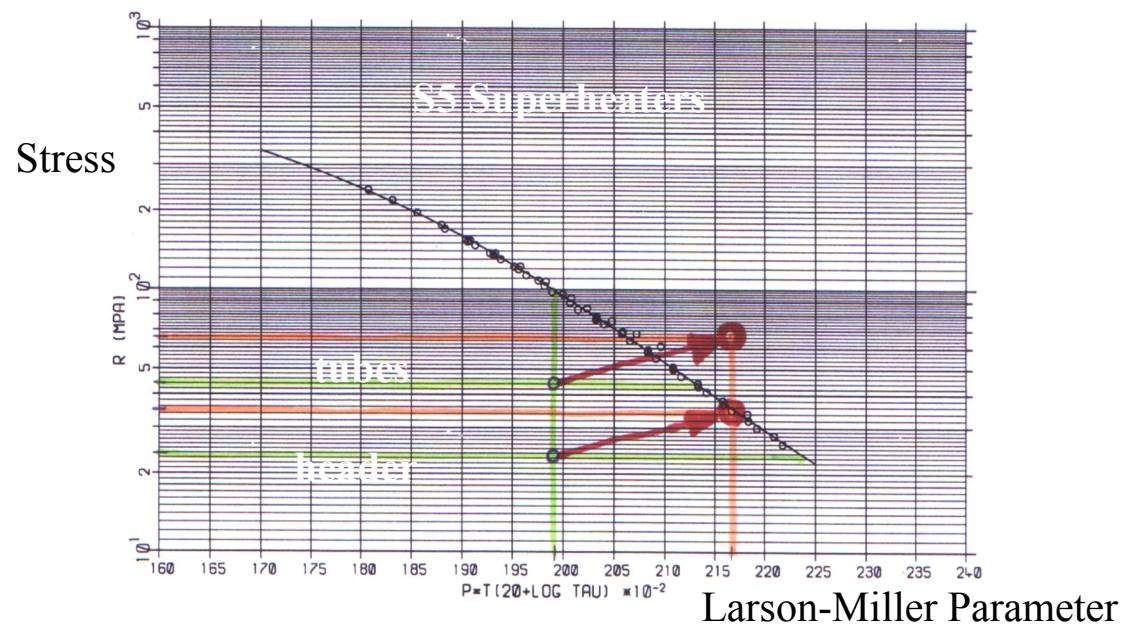

Figure 3: $\quad$ Stress vs. Larson-Miller Parameter relationship, Superheater S5.

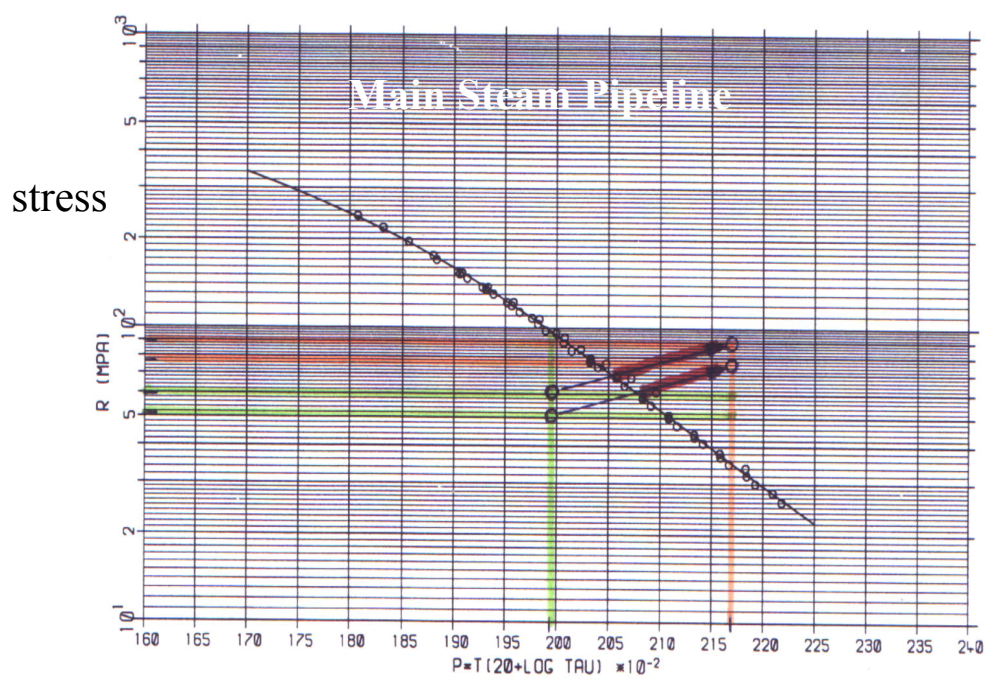

Larson-Miller Parameter

Figure 4: Stress vs. Larson-Miller Parameter relationship, Main Steam Pipeline. 
Table 1: $\quad$ Residual lifetime evaluation results.

\begin{tabular}{|c|c|c|}
\hline Component & $\begin{array}{c}\text { Residual Life } \\
\text { Evaluation } \\
\text { /YEARS/ }\end{array}$ & Recommendation \\
\hline Main Steam Pipeline I & $4-5$ & $\begin{array}{l}\text { Re-examination after } 20000 \mathrm{hrs} \\
\text { at the latest. Assessment correction. }\end{array}$ \\
\hline Main Steam Pipeline II & $3-4$ & $\begin{array}{l}\text { Re-examination after } 20000 \mathrm{hrs} \\
\text { at the latest. Assessment correction. }\end{array}$ \\
\hline Superheater Header S2 & 20 & No immediate action necessary \\
\hline Superheater Header S3 & 20 & No immediate action necessary \\
\hline Superheater Header S4 & $5-7$ & $\begin{array}{l}\text { Re-examination after } 20000 \mathrm{hrs} \\
\text { at the latest. Assessment correction. }\end{array}$ \\
\hline Superheater Header S5 & 4-6 & $\begin{array}{l}\text { Re-examination after } 20000 \mathrm{hrs} \\
\text { at the latest. Assessment correction. }\end{array}$ \\
\hline S4 HT SH Tubes & $5-7$ & $\begin{array}{l}\text { Re-examination after } 20000 \mathrm{hrs} \\
\text { at the latest. Assessment correction. }\end{array}$ \\
\hline S5 HT SH Tubes & $3-5$ & $\begin{array}{l}\text { Re-examination after } 20000 \mathrm{hrs} \\
\text { at the latest. Assessment correction. }\end{array}$ \\
\hline $\begin{array}{l}\text { Other "cold" } \\
\text { components }\end{array}$ & 20 & No immediate action necessary \\
\hline
\end{tabular}

\section{Conclusions}

1. S4 HT Superheater points of both the header and the tube banks, are far from the creep to rupture curve and even after taking into consideration the safety factor and temperature increase the resulting points are in the "safe" area of stress vs. LMP diagram.

2. S5 HT Superheater points of both the header and the tube banks are rather far from the creep to rupture curve but after taking into consideration the safety factor and temperature increase, the resulting point of the header falls directly on the stress to rupture curve and the point representing the situation of the tubes is far beyond the curve in the potentially dangerous area. The safe life of both components has been thus exhausted and further operation will be done with lower safety factor according to abovementioned methodology.

3. The main steam pipeline points are situated in the safe area when safety factor is not applied. If the safety factor and temperature increase are taken into consideration, both pipelines fall into unsafe area, safe lifetime was thus exhausted and further operation will be realized with decreasing safety.

4. "Low" temperature components, steam and mud drums, economiser, and also furnace water wall headers and tube banks were found to be in a relatively very good condition and replacement was not necessary if the boiler would be 
operated correctly and subjected to regular maintenance and inspections. The possible option to be decided by bthe power plant authorities is to replace the HT components, superheaters (headers and tubes) and also the main steam pipeline immediately during the respective (or next) overhaul, to make use of the possible material upgrade for a more creep-resistant alloy commonly used in boiler construction nowadays and to equalize by this way the remaining lifetime of all the boiler decisive components.

\section{References}

[1] Kasl J., Mentl V., Koc J., France P.: Testing of Tubes and Life Assessment Summary, Skoda Research Ltd. Technical Report No. VYZ/TZ/52/166/2005, Plzen, CZ, 2005

[2] Metallographic Examination Summary, Enclosure: Skoda Research Ltd. Technical Report No. VYZ/TZ/52/017/04, Plzen, CZ, 2004 